\title{
Clinical factors of drug resistance in juvenile myoclonic epilepsy
}

\author{
P Gelisse, P Genton, P Thomas, M Rey, J C Samuelian, C Dravet
}

Centre Saint Paul, 300 Bd de Sainte

Marguerite, 13009

Marseille, France

P Gelisse

P Genton

C Dravet

Clinique

Neurologique, $\mathbf{C H U}$

Pasteur, Nice, France

P Thomas

Service de Neurologie, CHU Timone,

Marseille, France

M Rey

Service de Psychiatrie J C Samuelian

Correspondence to: Dr P Genton

piergen@aol.com

Received 20 March 2000 and in revised form

20 July 2000

Accepted 7 September 2000

\begin{abstract}
Juvenile myoclonic epilepsy is a comparatively benign form of idiopathic generalised epilepsy. Little is known about the prevalence of difficult to treat or drug resistant patients. Among 155 consecutive patients with newly diagnosed juvenile myoclonic epilepsy evaluated between 1981 and 1998 and followed up for at least 1 year (61 men, 94 women; aged $15-70$ years, mean 33 (SD 10.3); onset of juvenile myoclonic epilepsy at the age of 14.5 (SD 3.7), range 6-26; follow up 1-52 years, mean 13.5 (SD 9.9)), there were 15 pseudoresistant patients $(9.7 \%$ : lack of compliance (eight), insufficient treatment (three), abnormal lifestyle (four)) and 24 patients $(15.5 \%)$ who had persisting seizures despite adequate therapy and lifestyle. Clinical features associated with drug resistance were (1) the presence of psychiatric problems $\left(58.3 \% v 19 \% ; \chi^{2} \mathrm{p}<0.001\right)$ and (2) independently, the combination of seizure types (Fischer's exact 2 by 4, $\mathbf{p}=0.0026$ ). Three types were present in $62.5 \%$ of resistant patients versus $23.3 \%$ in non-resistant patients $\left(\chi^{2}, \mathbf{p}=0.0001\right)$. None of the resistant patients had myoclonic jerks as the only seizure type or a combination of absences and myoclonic jerks. Family history of epilepsy, age at onset of seizures, sex, presence of photoparoxysmal response, results of conventional neuroimagings (CT and MRI), and delayed diagnosis were not significantly associated with drug resistance. There is thus a significant subgroup of patients with juvenile myoclonic epilepsy who pose difficult therapeutic problems, and the prevalence of resistant cases may be increased in the experience of a referral epilepsy centre.

(F Neurol Neurosurg Psychiatry 2001;70:240-243)
\end{abstract}

Keywords: juvenile myoclonic epilepsy; drug resistance; prognosis

According to the International League Against Epilepsy, ${ }^{1}$ juvenile myoclonic epilepsy is an idiopathic generalised epilepsy characterised by a genetic predisposition, no evidence of neurological or intellectual deficit, and an average age at onset around puberty. Seizures are massive myoclonic jerks in $100 \%$ of the patients, generalised tonic-clonic seizures in $80 \%$, absence seizures in $25 \%$, and photoparoxysmal response in $40 \%$. The seizures may be precipitated by various stimuli such as sleep deprivation, fatigue, alcohol intake, and stress. ${ }^{1-5}$ Valproate is very effective in controlling seizures. The main reason for treating patients with juvenile myoclonic epilepsy with drugs other than valproate is the occurrence of side effects such as tremor, weight gain, and loss of hair. ${ }^{3}$ Used alone, valproate leads to total control of seizures in about $80 \%$ of the patients. ${ }^{3-5}$ However, some difficult to treat or drug resistant patients exist, particularly in the experience of referral centres such as ours, although they belong to common clinical experience. Little is known about the prevalence and the risk factors of drug resistance or intractability in juvenile myoclonic epilepsy, and the probable selection of difficult cases gave us the opportunity to try and define risk factors.

\section{Patients and methods}

We retrospectively analysed the records of patients who had been referred for the first time between 1981 and 1998 to two epilepsy centres (Marseilles, Nice). The diagnosis of juvenile myoclonic epilepsy was based on the criteria of the International Classification of Epilepsies ${ }^{1}$ and on classic treaties. ${ }^{2}{ }^{3}$ Over a period of 17 years, we found 170 consecutive cases. Among them, only patients who had a minimum follow up of 1 year since seizure onset have been evaluated for this study. The population was divided into three groups: (1) fully controlled, (2) truly resistant defined as persisting seizures (myoclonic jerks and/or absence seizures and/or generalised tonicclonic seizures) despite adequate lifestyle and treatment that included adequate doses of valproate, (3) pseudoresistant due to inadequate lifestyle, to low compliance, or to inadequate choice of drugs. Patients were not systematically and prospectively evaluated by a psychiatrist at referral or during follow up at our centres. However, the consulting neurologist systematically noted the existence of psychological, psychiatric, or behavioural problems, and whenever these had been mentioned in the medical record, they were further investigated by a psychiatrist to clarify the psychiatric diag- 
Clinical features associated with drug resistance

\begin{tabular}{|c|c|c|}
\hline & Non-resistant & Resistant \\
\hline $\begin{array}{l}\text { Population (total }=155 \text { cases, } 15 \text { cases were } \\
\text { pseudoresistant) }\end{array}$ & $116(74.8 \%)$ & $24(15.5 \%)$ \\
\hline Psychiatric disorders $\left(\chi^{2}, \mathrm{p}<0.0001\right)$ & $22(19 \%)$ & $14(58.3 \%)$ \\
\hline Severe mental retardation & 1 & 0 \\
\hline Pervasive developmental disorders & 0 & 2 \\
\hline Psychotic disorders & 2 & 0 \\
\hline Generalised anxiety & 3 & 3 \\
\hline Personality disorders & 12 & 6 \\
\hline Dependent personality & 3 & 1 \\
\hline Obsessive-compulsive personality & 0 & 1 \\
\hline Histrionic personality & 2 & 0 \\
\hline Paranoiac personality & 1 & 0 \\
\hline Borderline personality & 3 & 3 \\
\hline Personality disorder not specified & 3 & 1 \\
\hline Depressive disorders & 1 & 2 \\
\hline Tic disorders & 0 & 1 \\
\hline Enuresis & 1 & 0 \\
\hline Anorexia nervosa & 2 & 0 \\
\hline \multicolumn{3}{|l|}{ Seizure types (Fisher exact 2 by $4, p=0.0026)$ : } \\
\hline $\operatorname{GTCS}+\mathrm{AS}+\mathrm{MJ}\left(\chi^{2}, \mathrm{p}<0.001\right)$ & $27(23.3 \%)$ & $15(62.5 \%)$ \\
\hline GTCS + MJ & $71(61.2 \%)$ & $9(37.5 \%)$ \\
\hline $\mathrm{AS}+\mathrm{MJ}$ & $6(5.2 \%)$ & 0 \\
\hline MJ & $12(10.3 \%)$ & 0 \\
\hline \multicolumn{3}{|c|}{ Seizure types in patients with psychiatric problems ${ }^{\star}$ : } \\
\hline GTCS+AS+MJ & $3(13.7 \%)$ & $8(57.1 \%)$ \\
\hline GTCS + MJ & $17(77.3 \%)$ & $6(42.9 \%)$ \\
\hline $\mathrm{AS}+\mathrm{MJ}$ & 0 & 0 \\
\hline MJ & $2(9 \%)$ & 0 \\
\hline \multicolumn{3}{|c|}{ Seizure types in patients without psychiatric problem ${ }^{\star}$ : } \\
\hline $\mathrm{GTCS}+\mathrm{AS}+\mathrm{MJ}$ & $24(25 \%)$ & $7(70 \%)$ \\
\hline GTCS $+M J$ & $54(57.5 \%)$ & $3(30 \%)$ \\
\hline $\mathrm{AS}+\mathrm{MJ}$ & $6(6.5 \%)$ & 0 \\
\hline MJ & $10(11 \%)$ & 0 \\
\hline
\end{tabular}

GTCS $=$ Generalised tonic-clonic seizures; $A S=$ absence seizures; $M J=$ myoclonic jerks .

*There is no statistical difference between the patients with and without psychiatric problems. The combination of three seizure types and the presence of psychiatric problems are independently factors of resistance. valproate. One hundred and sixteen (74.8\%) patients were fully controlled (group 1) whereas $24(15.5 \%)$ had persistent seizures (group 2). Family history of epilepsy among first and second degree relatives $(35 \%$ in group $1 v 37.5 \%$ in group 2), age at onset of seizures (median 14 years in each group), sex (females $60 \%$ in group $1 v 62.5 \%$ in group 2), presence of photoparoxysmal response $39 \%$ in each group), and delay of diagnosis since seizure onset (mean 8 (SD 7.5) in group $1 v 8.5$ (SD 6.7 ) in group 2) were not significantly associated with drug resistance.

Non-specific abnormal neuroimaging findings were found in nine patients including a common arachnoid cyst (three), a mild ventricular enlargement (three), a mild diffuse cerebral atrophy and ventricular enlargement (one), a mildly increased T2 signal in the left temporal lobe (one), and a septum lucidum cavum (one). One patient had severe brain damage related to perinatal distress. In three patients, the neuroimaging was abnormal but related to a specific insult or disease with onset after epilepsy. Two patients had experienced severe head trauma unrelated to epileptic seizures after the onset of juvenile myoclonic epilepsy. Both had lesions related to the trauma and one of these two patients started partial seizures related to a wide left hemispheric contusion at 30 years of age. One patient had a typical form of multiple sclerosis responsible for a severe handicap. He has been seizure free for many years. All the patients with abnormal neuroimaging findings were fully controlled and the course of the disease was benign. Thus, none of the abnormal neuroimaging findings seemed to be relevant for the clinical expression and evolution of juvenile myoclonic epilepsy.

The table presents clinical features associated with poor seizure control despite adequate treatment, compared with patients with good control. Combination of seizure types was statistically significant (Fisher's exact 2 by 4 , $\mathrm{p}=0.0026$ ). More precisely, the presence of three types of seizures was associated with drug resistance, and was found in $62.5 \%$ of resistant cases $v 23.3 \%$ in non-resistant cases, $\left(\chi^{2}\right.$ test, $\mathrm{p}=0.0001)$. None of the resistant patients had myoclonic jerks as the only seizure type or a combination of absence seizures and myoclonic jerks. Psychiatric disorders were found in $58.3 \%$ of resistant patients and only in $19 \%$ of non-resistant patients ( $\chi^{2}$ test, $\left.\mathrm{p}<0.0001\right)$. Six patients with serious psychiatric disorders including psychosis (two), severe mental retardation (one), and anorexia nervosa (two) were classified as non-resistant whereas two with a pervasive mental disorder were classified as resistant. Personality disorders were the most frequent finding (table) and were detected in $25 \%$ and $10.3 \%$ of resistant and non-resistant cases, respectively (Fisher's exact test, $\mathrm{p}=0.09$ ). Among them, a borderline personality responsible for social maladjustment represents the most frequent personality disorder. It was found more often in patients with drug resistance but the difference was not significant $(12.5 \%$ v $2.6 \%$ in non-resistant cases (Fisher's 
exact test, $\mathrm{p}=0.06)$ ). Three other patients with a borderline personality had persisting seizures due to a bad compliance and were classified as pseudoresistant. Generalised anxiety was diagnosed in $12.5 \%$ of patients with drug resistance and in $2.6 \%$ in non-resistant patients (Fisher's exact test, $p=0.06$ ). Finally, if taken together, personality disorders and generalised anxiety were significantly more frequent in patients with drug resistance $37.5 \%$ v 13\% (Fischer's exact test, $\mathrm{p}=0.007)$ ). Among the 36 patients who had psychiatric problems, $11(31 \%)$ had three types of seizures, 23 (64\%) had two types, and two (5\%) had one type, versus $31(30 \%)$, $63(60.4 \%)$, and $10(9.6 \%)$, respectively, in patients without psychiatric disorders. The comparison clearly shows that presence of psychiatric disorders and combination of seizure types are independent factors of resistance (table).

\section{Discussion}

Overall, juvenile myoclonic epilepsy is not considered a severe condition and drug resistance should raise doubts about diagnosis, lifestyle, compliance, and insufficient or inadequate treatment. However, true resistance to adequate drugs is not uncommon, and was found in $15.5 \%$ of this series of consecutively diagnosed patients. Our findings are in accordance with the experience reported by others, who found that $76-88 \%$ were controlled on valproate monotherapy. ${ }^{78}$ There are few studies mentioning the features associated with poor seizure control in patients with juvenile myoclonic epilepsy. Dasheiff and Ritaccio ${ }^{9}$ reported on 12 patients with intractable juvenile myoclonic epilepsy and found a long duration of epilepsy in these patients (mean 21 years) - during which the diagnosis and appropriate treatment were delayed - and a high percentage of asymmetric or focal discharges on scalp EEGs. They emphasised that juvenile myoclonic epilepsy is not necessarily a benign epilepsy and alternative therapies, such as surgery, may be considered. We do not agree. Even if there is a considerable interest in the possibility that juvenile myoclonic epilepsy as well as other forms of idiopathic generalised epilepsy can be associated with cortical microdygenesias, ${ }^{10}$ juvenile myoclonic epilepsy is a genetically determined generalised epilepsy that is not amenable to surgery. Moreover, in their study, almost all patients (9/12) were on inadequate drugs such as carbamazepine and/or phenytoin in monotherapy or in association with valproate, phenobarbital, and a benzodiazepine. According to our classification, they would have been classified as pseudoresistant. Patients treated with phenytoin or carbamazepine should not be considered as having a resistant form of juvenile myoclonic epilepsy. Using adequate drugs can dramatically improve juvenile myoclonic epilepsy. Delayed diagnosis does not seem to represent a risk factor of resistance in our data because patients were not evaluated at referral but at the end of the follow up period after an appropriate treatment had been given.
The presence of all three seizure types seems to be a risk factor, whereas myoclonic jerks alone (10\% in this study) or a combination of absences and myoclonic jerks $(5.2 \%$ in this study) is not. This is in accordance with Matsuoka ${ }^{11}$ who reported an excellent prognosis in patients with absence seizures and myoclonic jerks among 32 patients with juvenile myoclonic epilepsy treated by valproate monotherapy or in combination with other antiepileptic drugs. The seizures were well controlled for 3 years in the patients with absence seizures (100\%) compared with those with generalised tonic-clonic seizures (55\%) and those with generalised tonic-clonic seizures and absences $(31 \%)$. Jain et al ${ }^{12}$ studied 15 patients with juvenile myoclonic epilepsy with myoclonic jerks alone and they hypothesised that those presenting with only early morning myoclonic jerks may represent a benign variant.

Mild but characteristic personality problems were initially described in patients with juvenile myoclonic epilepsy by Janz and Christian ${ }^{13}$ and confirmed by other authors (see review by Janz and Durner ${ }^{4}$ ). More serious psychiatric problems are less common. In our series, the presence of psychiatric disorders seems to be a strong factor for drug resistance. This factor had not previously been quoted as causing a poorer response to drug treatment. This element was evaluated separately from poor compliance, which was either corrected or (if persistent) considered by us a factor of "pseudoresistance". Psychiatric disorders clearly represent a newly recognised element of poor seizure control, independent of combination of seizure types. Juvenile myoclonic epilepsy is a chronic disorder that may require lifelong therapy. ${ }^{34}$ Evolution may be fluctuating and some patients with a benign form can have a transient period of worsening whereas others who are more difficult to treat may later experience spontaneous improvement. One of our patients, who had congenital hypothyroidism, experienced myoclonic status (plasma concentration of valproate $90 \mathrm{mg} / \mathrm{l}$ ) when thyroid replacement therapy was stopped. Piracetam and hormone replacement led to full control within a few days. He was seizure free at the end of the follow up and was considered as fully controlled (group 1), although he had been transiently resistant, with hypothyroidism the probable cause. Another patient experienced his first seizure at 16 years of age, when valproate was started and led to a remission that lasted until the age of 27. Then his epilepsy became active. No cause was found to explain this worsening. He was considered at the end of the follow up to have a resistant form (group 2 ). We were unable to investigate the variations of responses to drugs for all patients because in a few cases, information such as plasma concentrations in periods of aggravation were not available. In this retrospective study, we only analysed the response to drugs at the end of follow up for each subject, and thus give only an imperfect picture of reality. Further analyses taking account of this fluctuating evolution are 
necessary to identify the clinical significance of seizure recurrence in juvenile myoclonic epilepsy.

\section{Conclusions}

There is a significant subgroup of patients with juvenile myoclonic epilepsy who pose difficult therapeutic problems. Among these, some may be considered as pseudoresistant, due to various factors that prevent the use of adequate doses of drugs. Others (15.5\% in this series) may be considered as truly resistant. Among clinical factors leading to the persistence of seizures in patients with juvenile myoclonic epilepsy despite adequate treatment, we found that two independent situations were significantly associated with a poor therapeutic control: (1) the coexistence of all three seizure types (myoclonic jerks, absence seizures, and generalised tonic-clonic seizures) - there were no cases of drug resistance in patients experiencing only isolated myoclonic jerks or a combination of myoclonic jerks and absence seizures - and (2) the existence of psychiatric problems.

This work was supported in part by a research grant from the French League Against Epilepsy and from the Janssen-Cilag
Company, France, and was presented in part at the 23rd International Epilepsy Congress, Prague, 12-17 September 1999.

1 Commission on Classification and Terminology of the International League Against Epilepsy. Proposal for revised classification of epilepsies and epileptic syndromes. Epilepsia 1989;30:389-99.

2 Janz D. Die Epilepsien. Stuttgart: Thieme, 1969.

3 Wolf P. Juvenile myoclonic epilepsy. In: Roger J, Bureau M, Dravet Ch, et al, eds. Epileptic syndromes in infancy, childhood and adolescence. 2nd ed. London: John Libbey, 1992:31327.

4 Janz D, Durner M. Juvenile myoclonic epilepsy. In: Engel JR, Pedley TA, eds. Epilepsy: a comprehensive textbook. Philadelphia: Lippincott-Raven, 1997:2389-400.

5 Genton P, Gélisse Ph, Thomas P. Juvenile myoclonic Genton P, Gélisse Ph, Thomas P. Juvenile myoclonic
epilepsy today. In: Schmitz B, Sander T, eds. Fuvenile myoepilepsy today. In: Schmitz B, Sander T, eds. Fuvenile myo-
clonic epilepsy : the fanz syndrome. Petersfield, UK: Wrightclonic epilepsy : the fanz syndro
son Biomedical, 2000:11-32.

6 American Psychiatric Association. Diagnostic and statistical manual IV. Washington DC: American Psychiatric Association, 1994

7 Delgado-Escueta AV, Enrile-Bacsal F. Juvenile myoclonic epilepsy of Janz. Neurology 1984;34:285-94.

8 Panayiotopoulos CP, Obeid T, Tahan AR. Juvenile myoclonic epilepsy: a 5-year prospective study. Epilepsia 1994;35:285-96.

9 Dasheiff RM, Ritaccio AL. Characterization of intractable JME: new perspectives on primarily generalized seizures. Seizure 1993;2:11-19.

10 Meencke HJ, Janz D. Neuropathological findings in primary generalized epilepsy: a study of eight cases. Epilepsia 1984; 25:8-21.

11 Matsuoka $\mathrm{H}$. The seizure prognosis of JME. fapanese fournal of Psychiatry and Neurology 1992;46:293-6.

12 Jain S, Padma V, Maheshwari MC. Occurrence of only Jain S, Padma V, Maheshwari MC. Occurrence of only
myoclonic jerks in juvenile myoclonic epilepsy. Acta Neurol myoclonic jerks in juve

13 Janz D, Christian W. Impulsiv Petit Mal. Dtsch Z Nervenheik 1957;176:346-86. 